Article

\title{
Distributed Generation and Optimization of smart Grid Sys- tems: Case Study of Kumba in Cameroon
}

\author{
Abraham Dandoussou ${ }^{1,2, *}$, Pierre Kenfack ${ }^{1}$, George Lekunze Toh ${ }^{1}$ \\ ${ }^{1}$ Higher Technical Teachers' Training College (HTTTC), University of Buea, Kumba, Cameroon \\ ${ }^{2}$ School of Chemical Engineering and Mineral Industries (SCEMI), University of Ngaoundere, Cameroon. \\ *Correspondence: Abraham.dandoussou@ubuea.cm
}

How to cite this paper: Dandoussou, A., Kenfack, P., \& Lekunze Toh, G. (2021). Distributed Generation and Optimization of Smart Grid Systems: Case Study of Kumba in Cameroon. World Journal of Electrical and Electronic Engineering, 34-43. Retrieved from https://www.scipublications.com/journal/in-

dex.php/wjeee/article/view/126

Received: August 17, 2021

Accepted: September 22, 2021

Published: September 23, 2021

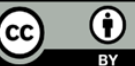

Copyright: (c) 2021 by the authors. Submitted for possible open access publication under the terms and conditions of the Creative Commons Attribution (CC BY) license (http://creativecommons.org/licenses /by/4.0/).

\begin{abstract}
The traditional electric grid of the City of Kumba has been experiencing a constant failure which leads inhabitant to experience constant blackout. This constant blackout persists and stays for a long time due to the lack of communication between equipment, consumer and supplier. Whenever there is a fault, the repairing agents walk along the feeder to find the fault. This manual fault finding increases the restauration time which leads to the augmentation of the blackout period. Factors responsible for the failure of the line are complex to be controlled. It is necessary to reduce restauration time by introducing Information and Communication Technologies (ICT) and sensing system in the grid and making it to be smart. ICT in this smart grid, sensors and smart meters are meant to assure two-way communication between the supplier and the consumer. They send real time information which is computed at the control center to optimize the entire grid. Distributed generation is also introduced in the system for two purposes. To complete the lag in power demand of the grid and to take over the supply when the main feeder is faulty. Various distributed generation sources studied led to the choice of solar power plants thanks to their low production of Greenhouse Gas (GHG) and availability of their resources in the city. A model has been proposed for the distributed generation and optimization of the smart grid. The system indexes obtained without distributed generation in the grid are different from that with. The difference in these indexes proved that the grid has been optimized. However, the reliability of the grid is enhanced after the introduction of distributed generation into the system. This enhancement in reliability declares that with distributed generation into the grid, the population of Kumba has a reliable power supply, which makes them to have energy throughout.
\end{abstract}

Keywords: Distributed generation, optimization, smart grid, reliability

\section{Introduction}

Electricity in the City of Kumba is currently supplied by one feeder coming from Limbe. This feeder passes through many villages as well as bushes. Falling of trees, circulation of animal and disasters like lightening, wind and water contribute to the constant failure of the feeder. Besides these disasters, human beings play another part in the constant failure of the entire grid. This contribution is due to the hazardous bushfire set during cultivating periods. These natural and human causes generate constant failure to the feeder. Availability of a single feeder to the city yields to its blackout whenever it is faulty. This leads consumers to experience unreliable electricity supply.

The presence of smart grid into the system will assure autonomous control actions to enhance reliability by increasing resiliency against component failures and natural disasters actions [1]. It is a grid that uses digital technology to improve reliability, security, and efficiency of the electric system from large generation, through the delivery systems 
to electricity consumers and a growing number of distributed generation and storage resources [1].

Looking forward to a reliable energy, distributed generation (DG) has been proposed. It is an electric power generation source connected directly to the distribution network or on the customer side [2]. These sources are renewable energy and are made up of solar energy, wind energy, marine and hydro power, bio-energy and fuel, geothermal, energy storage and combined heat \& power, which are incorporated into the grid [3-7]. Their presence will contribute to solve the equation of reducing Greenhouse Gas (GHG), which contributes to pollution of the environment. For reliability analysis, a methodology is proposed in [8] where reliability indexes of the distribution network were computed with the integration of DG. It is shown in [9] that more reliable and inexhaustible power can be provided to consumers by integrating distributed renewable energy resources and energy storage devices into the power grid. The effect of smart grid applications in enhancing the reliability of distribution networks using Monte Carlo simulation method is studied in [10]. Studies carried out by authors in [11] resulted that both distributed generation units and the installation of automatic sectionalizing devices will provide more intelligent and reliable power system distribution network. In contrast to other authors who proved that the ultimate way for reliability improvement of a smart grid was the integration of DG and energy storage devices, authors in [12] affirmed that reliability could be enhanced without the presence of DG, but realized themselves earlier by affirming that the integration of DG was more reliable.

In this work, smart grid will be studied with its application to the City of Kumba. Distributed generation made up of two solar farms will be applied to this smart grid, then its reliability will be evaluated.

\section{Materials and Methods}

\subsection{Smart grid in the City of Kumba}

The current traditional electric grid supplying the City of Kumba will experience the integration of sensors. The function of these sensors shall be to measure a wide variety of physical parameters across the entire grid. They will provide real-time data and status of the grids for real-time monitoring, protection, and control of grid operations.

A control center constructed will host all the monitoring, protection, and control of grid operations. Wide Area Network (WAN) will take charge of these operations which will ensure communication between all the sensors introduced in grid and the control center. Supervisory Control and Data Acquisition (SCADA), which is a core component in the control center, will allow the utility to remotely monitor and control network devices as a means of achieving reliability and demand efficiencies for the utility as a whole.

Smart meters installed in the grid will record information such as consumption of electric energy, voltage level, current, and power factor. They will communicate the information to the supply authority for greater clarity of consumption behavior, and electricity suppliers for system monitoring and consumer billing. Since smart meters enable twoway communication between the meter and the supplier, they shall typically record energy near real-time and report regularly in short intervals throughout the day. 


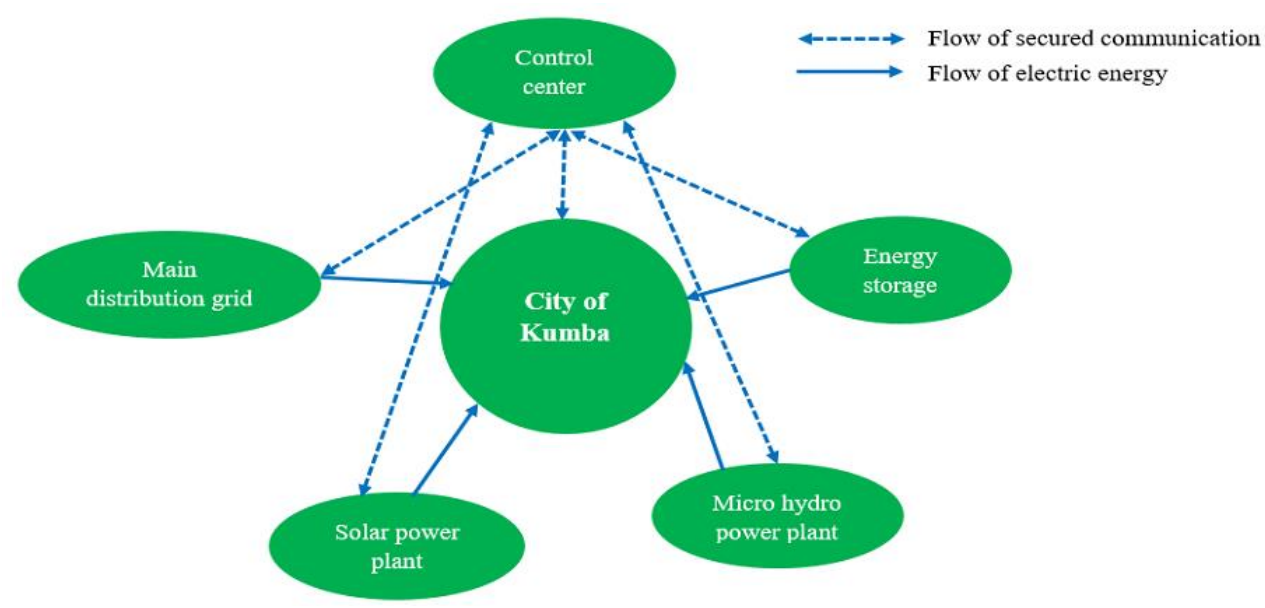

Figure 1. A conceptual model for smart grid in Kumba

The smart grid in the City of Kumba comprises an integration of ICT, sensors and DG in the existing grid. ICT assures two-way communication through sensors between the main feeder, DG, utility and control center. Electric energy produced by DG serves for the supply of the city, in addition to the current feeder. Figure 1 shows a conception model of flow of communication and electricity in the new grid.

\subsection{Distributed Generation in the City of Kumba}

Two feeders were supplying the City of Kumba. The main distribution line coming from Loum and another one coming from Limbe with the capacity of $23 \mathrm{MW}$ for the City and its environs. The two lines were working alternatively and one was taking over when another one was faulty. The electric grid supplying the city of Kumba is a traditional grid. Its power demand is about 15 MW. Since 2018, the feeder line from Loum is faulty and the feeder coming from Limbe now supplies the entire city.

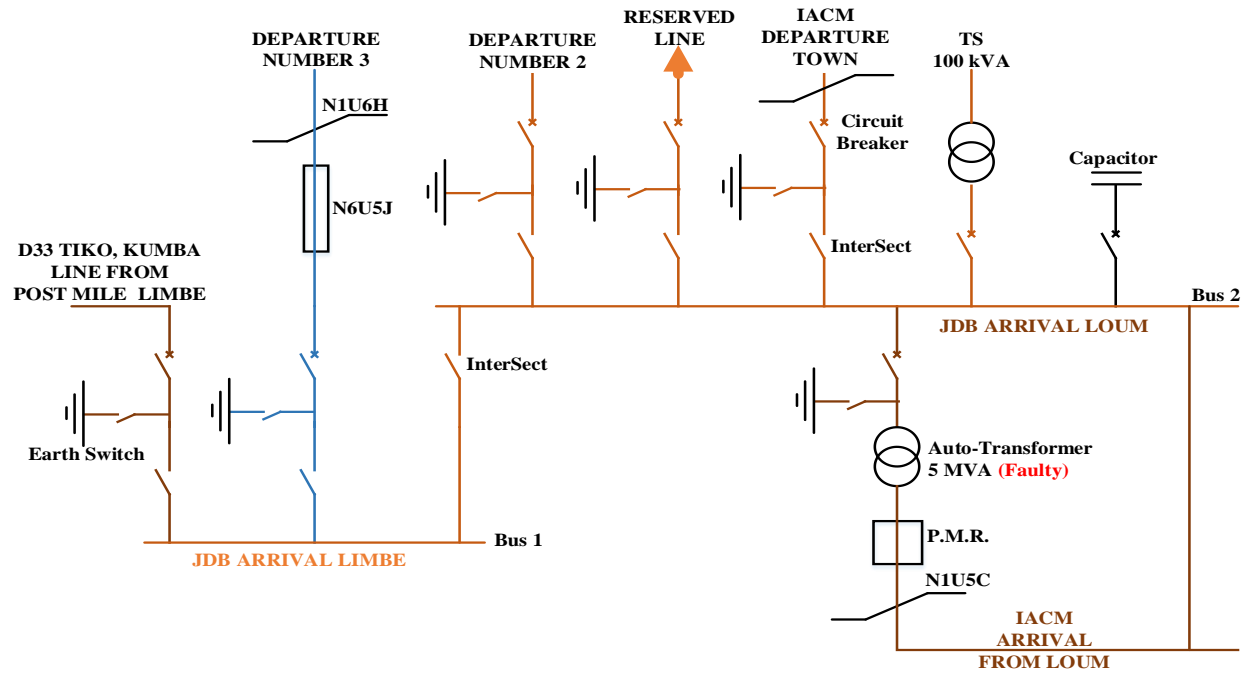

Figure 2. Current supply grid to the city of Kumba

Beside the main traditional electric grid supplying the city of Kumba, two solar power plants are added to the grid of this city. Since the feeder from Loum is faulty, it is excluding for this study. Throughout the study, the city of Kumba is considered as a single load. 


\subsection{Modeling of the DG in the city of Kumba}

The model is comprised of two DG systems added to the main grid. The DG systems are two solar power plants of capacity of $10 \mathrm{MW}$ and $5 \mathrm{MW}$ respectively. These solar power plants have energy storage systems of $10 \mathrm{MW}$ and $5 \mathrm{MW}$ for DG1 and DG2 respectively. They are incorporated to these plants to operate in the night to satisfy the demand since solar plants do not generate electricity in the night due to the total absence of sunlight. The energy storage system also serves in balancing the power demand when the DG is operating and weather is not favorable for solar plants to satisfy the demand.

When the main feeder is faulty, auto switches at the substation close and enable the DG to supply the entire city. Part of the city remains supplied when the main feeder is faulty and simultaneously, one of the DG systems is faulty. During the day, the demand is lower than the supply when DG systems are operating. The rest of energy used to charge storage batteries.

The city of Kumba is a residential city, meaning there is no major industry available in the city. The main energy usage is in residences. Being an active town where the majority of population goes to work in the day and only comes back at night, the peak demand of power is at night, from $6 \mathrm{pm}$ to $11 \mathrm{pm}$.

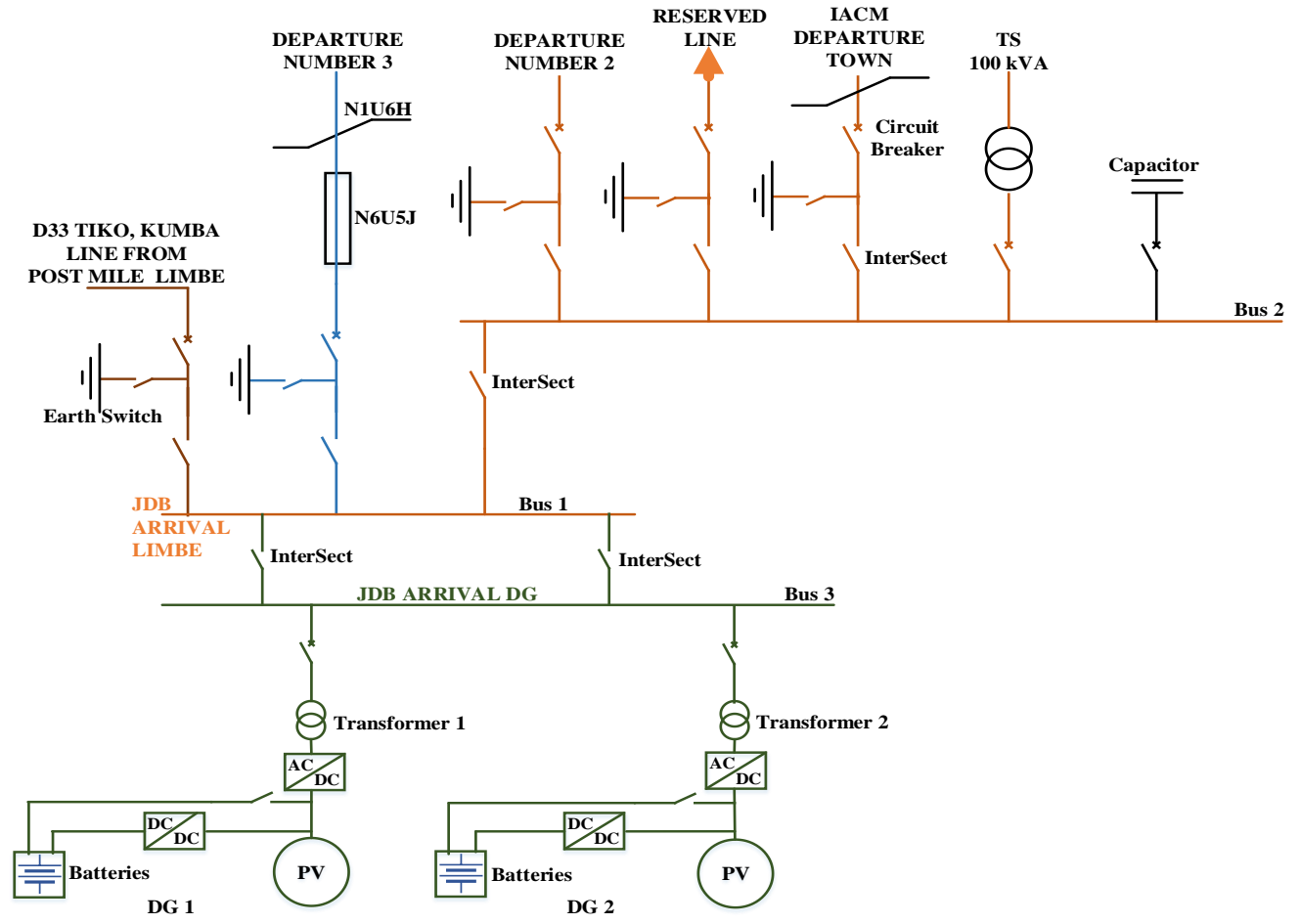

Figure 3. Model of DG in the city of Kumba

\subsection{Optimization of the Smart grid}

The main challenge of electricity in the city of Kumba is at the level of reliability of energy supply. Its optimization is performed on the evaluation of the reliability of electricity in the city with implementation of DG.

\subsubsection{Reliability Evaluation}

The reliability evaluation of the Smart grid in the city of Kumba is done with the probability of failure of the supply grid. The first evaluation is done without DG resources and the second evaluation with DG resources. 
Reliability indices taken into account are failure rate, outage duration and annual outage time on one hand, and SAIFI, SAIDI, ASAI and CAIFI on the other hand.

Calculation methods of these reliability indices are presented as follows: [9], [12-14]

- Average outage duration rate: $r_{s}=\frac{\sum \lambda_{i} r_{i}}{\sum \lambda_{i}}$

- Annual outage duration: $U_{s}=\sum \lambda_{i} r_{i}$,

- System Average Interruption Frequency Index (SAIFI) is the total customers interrupted divided by total customer served, and it is usually stated for the duration of a year. SAIFI $=\frac{\sum_{\lambda_{i}} N_{i}}{N_{T}}$ where $N_{i}$ and $N_{T}$ are the number of customers interrupted due to outage $i$ and total number of customers, respectively.

- $\quad$ System Average Interruption Duration Index (SAIDI) is the total customer interruption durations divided by total customers served, and it is usually stated for the duration of a year. SAIDI $=\frac{\sum \mathrm{U}_{\mathrm{S}} \cdot \mathrm{N}_{\mathrm{i}}}{\mathrm{N}_{\mathrm{T}}}$.

- Average Service Availability Index (ASAI) is the average availability of service per customer served by the utility. ASAI $=\frac{\mathrm{N}_{\mathrm{T}} \mathrm{T}-\sum_{\mathrm{i}} \mathrm{U}_{\mathrm{s}} \mathrm{N}_{\mathrm{i}}}{\mathrm{N}_{\mathrm{T}} \mathrm{T}}$ where $T$ is duration for reporting the index, which is usually one year, that is 8760 hours.

- Customer Average Interruption Frequency Index (CAIFI) is the total number of customer interruption divided by the total number of customers affected. CAIFI $=\frac{\mathrm{N}_{\mathrm{in}}}{\mathrm{N}_{\mathrm{af}}}$.

\subsubsection{Simulations Methodology}

The method used for the evaluation of the reliability of the system is Monte Carlo Simulation. The data required for this method includes statistical component failure and repair information, as well as system configuration [14]. The failure and repair histories of components are simulated using random variables with probability distributions of the component states, which mimic the random behavior of the system operation such as component failures, etc. [15]. Randomly generated samples of failures and restoration times based on the probability distribution of the statistical data provided are used to calculate one set of numeric results for reliability indices [14]. After having the calculation for one set, new random values are sampled from input probability distributions to generate new possible values for reliability until the expected reliability of the system is calculated.

Simulations were done into two steps using MATLAB code. The first step evaluated the reliability indices of the system without DG and the second and the second evaluated these indices with the integration of DG.

\section{Results}

\subsection{Load Point Output}

\subsubsection{Load Point Output Without DG}

Table 1 shows that feeder supplying the city Kumba from Limbe and its Circuit breakers situated at Ekona and Balangi for feeder breaker 1 and 2 respectively have the same average interruption rate. Whenever a pole along the line falls, it takes $5 \mathrm{~h} 30 \mathrm{~min}$ of maintenance for the line to be restored and the population experience 1-h blackout when the feeder breaker at Ekona is tripped meanwhile it takes 30 minutes for restoration energy when feeder's breaker at Balangi is faulty as illustrated. It shows that the feeder's line itself is at the cause of blackout in the city for more than 669 hours each year and tripping of line breakers disrupt energy for about 183 hours per year. 
Table 1. Load Point Output Without DG

\begin{tabular}{cccc}
\hline Component & Average interruption rate & Average outage duration & Annual outage duration \\
\hline ID & $\mathbf{f} / \mathbf{y r}$ & $\mathbf{h r}$ & $\mathbf{h r} / \mathbf{y r}$ \\
Feeder & 121.67 & 5.5 & 669.19 \\
Feeder breaker 1 & 121.67 & 0.5 & 060.84 \\
Feeder breaker 2 & 121.67 & 1.0 & 121.67 \\
\hline
\end{tabular}

\subsubsection{Load point output of DG}

Table 2 summarizes the load point output of DG. The average interruption rate, average outage duration and annual outage duration are the same for both DG1 and DG2. The main elements, directly linked to the energy disruption of the DG of the City are distribution line, line breaker, transformer and inverter as shown in table 2. Failure of one of these elements provokes instantaneously the failure of the entire system.

The load point output of this system indicates that distribution lines are well sophisticated and constructed using quality and durable materials. Their average failure rate is once in half century and when they fail, it takes 5 hours of maintenance for energy to be restored. Their annual outage duration is 0.01 hour per year.

The selected transformers for the system also have a probability of failing only one time every 50 years and it takes 4 hours each time any of them fail for maintenance to be accomplished. This makes any of them to have a possibility of causing an annual outage for a period of $4 \min 48 \mathrm{~s}$.

Voltage inverters used in the process for the conversion of DC voltage produced by the solar farm into AC could have failure every after 15 years for 2 hours only causing energy interruption of $8 \mathrm{~min} 24 \mathrm{~s}$ per year. The probability for line breakers to fail is 1.67 times each year for only $15 \mathrm{~min}$ and disrupting energy for 25 minutes 30 seconds every year.

Table 2. Load point output of DG

\begin{tabular}{cccc}
\hline Component & $\begin{array}{c}\text { Average interruption } \\
\text { rate }\end{array}$ & Average outage duration & Annual outage duration \\
\hline ID & $\mathbf{f} / \mathbf{y r}$ & $\mathbf{h r}$ & $\mathbf{h r} / \mathbf{y r}$ \\
\hline Distribution line & 0.020 & 5.00 & 0.0100 \\
Distribution line breaker & 1.670 & 0.25 & 0.4175 \\
Transformer & 0.020 & 4.00 & 0.0800 \\
Inverter & 0.067 & 2.00 & 0.1340 \\
\hline
\end{tabular}

\subsection{System indices}

The system average interruption frequency, as shown in figure 4, examines how frequent an interruption can occur in the grid per year. Its index gives information about reliability of the entire system. Without integrating DG into the smart grid, SAIFI is as high as 121.67 interruptions/system customer/yr. Results show that with DG into the system, its SAIFI is enhanced by $100 \%$.

The presence of DG in the smart grid of the City of Kumba transforms the grid into a reliable grid and enables consumers not to experience interruption. Interruption can occur only if either DG1 or GD2 is faulty coupled with the main feeder. Nevertheless, the SAIFI of the grid will still be enhanced by $99.53 \%$ when only DG1 is working and $99.03 \%$ when only DG2 supplies.

It is probable that at least one component of the system fails at a given time. One of the main factors affecting the reliability of the system is how long does the fault stay before 
being maintained. Due to some conditions among which unfavorable weather condition, lack of parts in the inventory, unavailability of the required facility or human error, the repair of the fault in the system may delay. This delay affects the system average interruption duration index.

Nevertheless, with the installation of DG, SAIDI (shown in figure 5) has decreased from $851.69 \mathrm{hr} /$ system customer/yr to $069 \mathrm{hr} /$ system customer/yr. Moreover, the new smart grid with the integration of two DGs still finds its SAIDI enhanced by $99.97 \%$ and $99.95 \%$ when only DG1 or DG2 is supplying respectively. Figure 5 describes the evolution of SAIDI then only the main feeder is working and when DGs are connected to the grid or when either one of the two DGs are the one supplying.

Results show that ASAI, shown in figure 6, has been improved from 0.90278 to 1 when DG is installed. The failure of the main feeder and DG2, allowing only DG1 to operate still enhance the ASAI of the supplied part by $10.77 \%$. When only DG2 is supplying the prioritized area of the city, its ASAI experiences an increase of $10.76 \%$.

Evaluating the ratio between the total number of customer interruption by the total number of customers affected is one of the key points for reliability analysis. CAIFI, as shown in figure 7 , for the traditional grid is 1 , showing that all customers are interrupted each time there is a fault in the system, causing the interruption of the feeder.

With the installation of DG in the smart grid, CAIFI becomes 0 , indicating that no customer is interrupted whenever there is a fault in the main feeder. If a fault occurs in one of the DGs when the main feeder is already faulty, the smart grid of the City will have a CAIFI of 0.33 when its DG2 which is faulty and 0.67 when its DG1 which is faulty.

Figure 8 shows the capacity of the DG in supplying the smart grid of the city of Kumba. The entire DG is capable of supplying the whole City as backup when the main feeder is faulty. 2/3 of the City could be supplied when the main feerder and DG2 are faulty and $1 / 3$ could also be energised if the fault is the feeder and DG1.

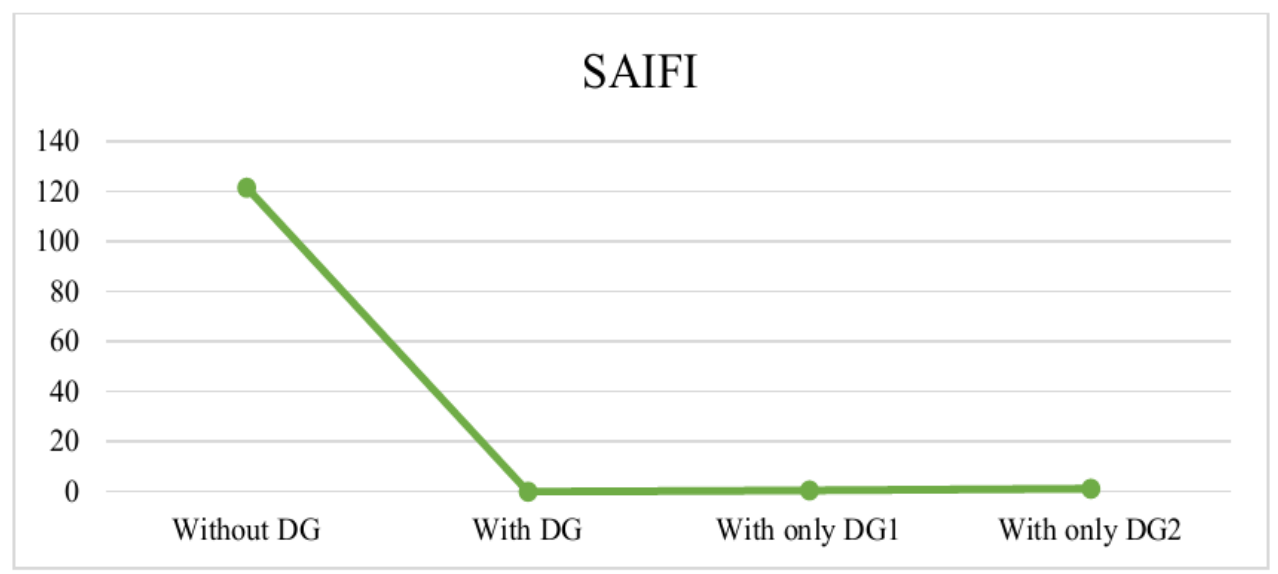

Figure 4. Results of SAIFI 


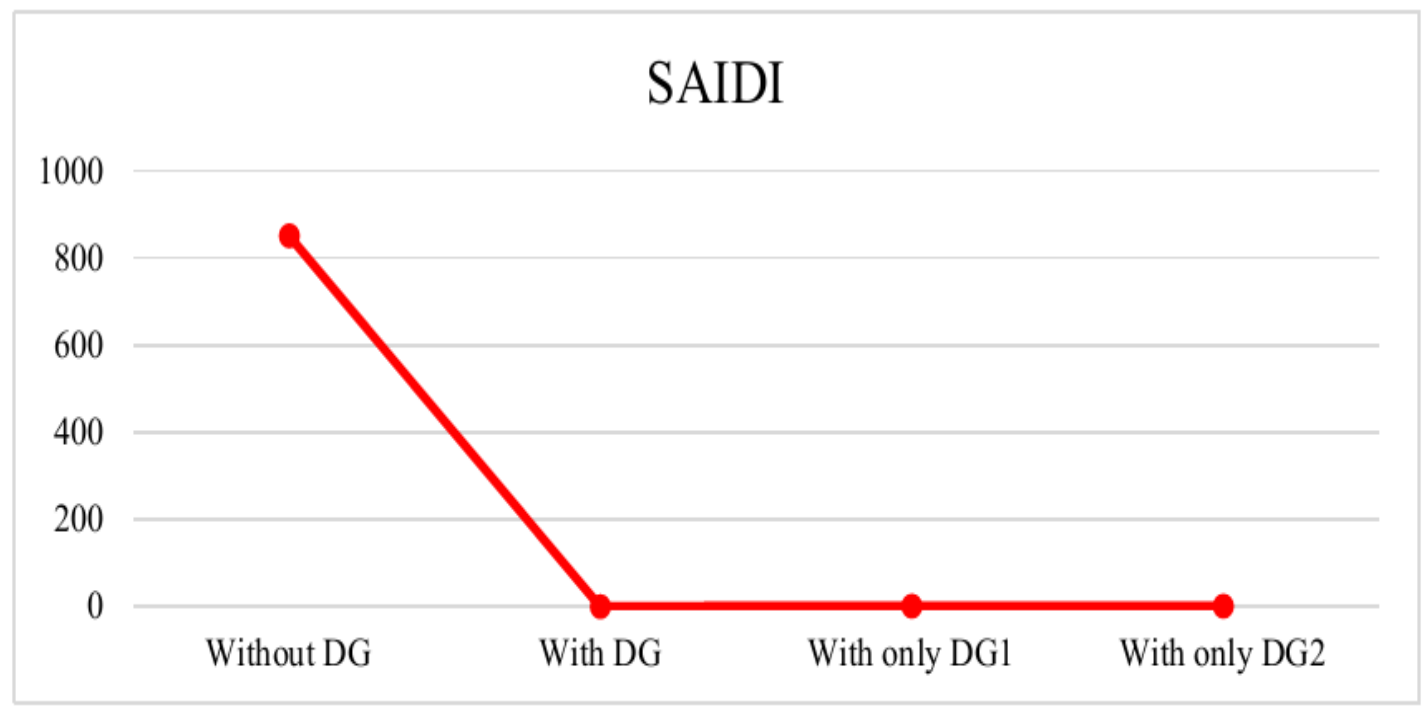

Figure 5. Results of SAIDI

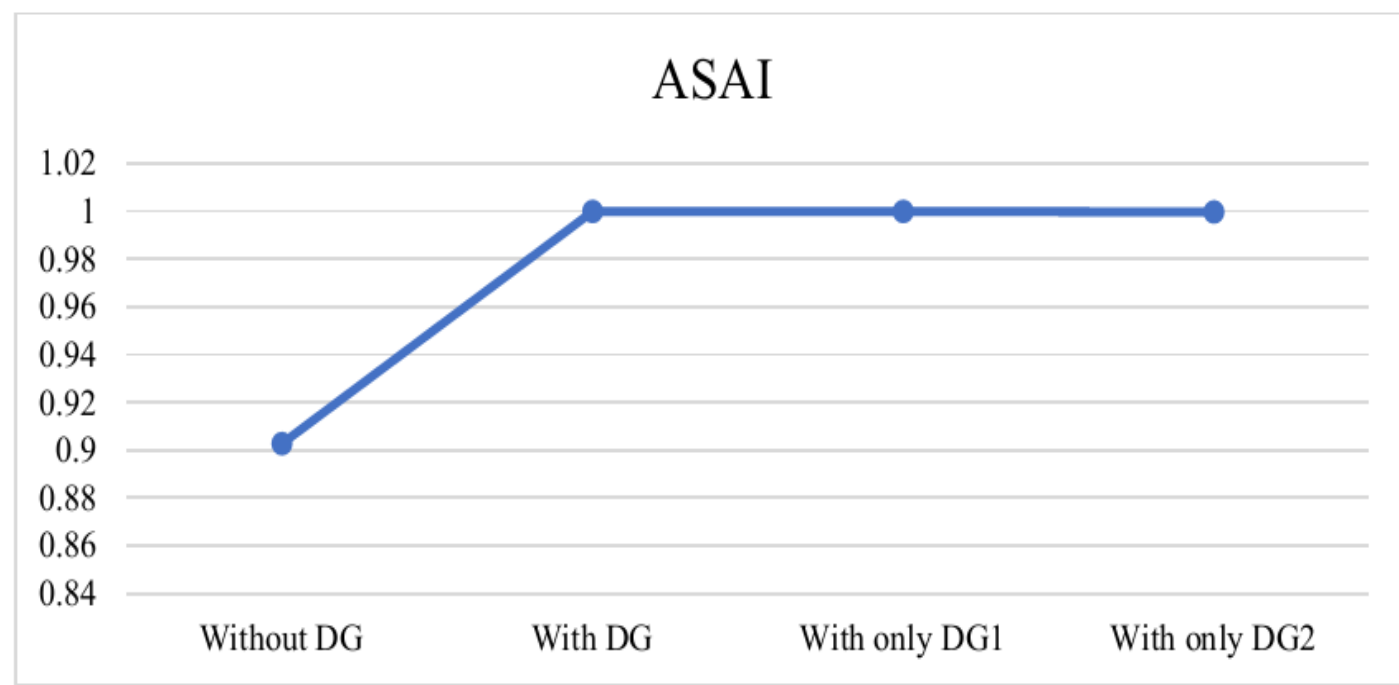

Figure 6. Results of ASAI

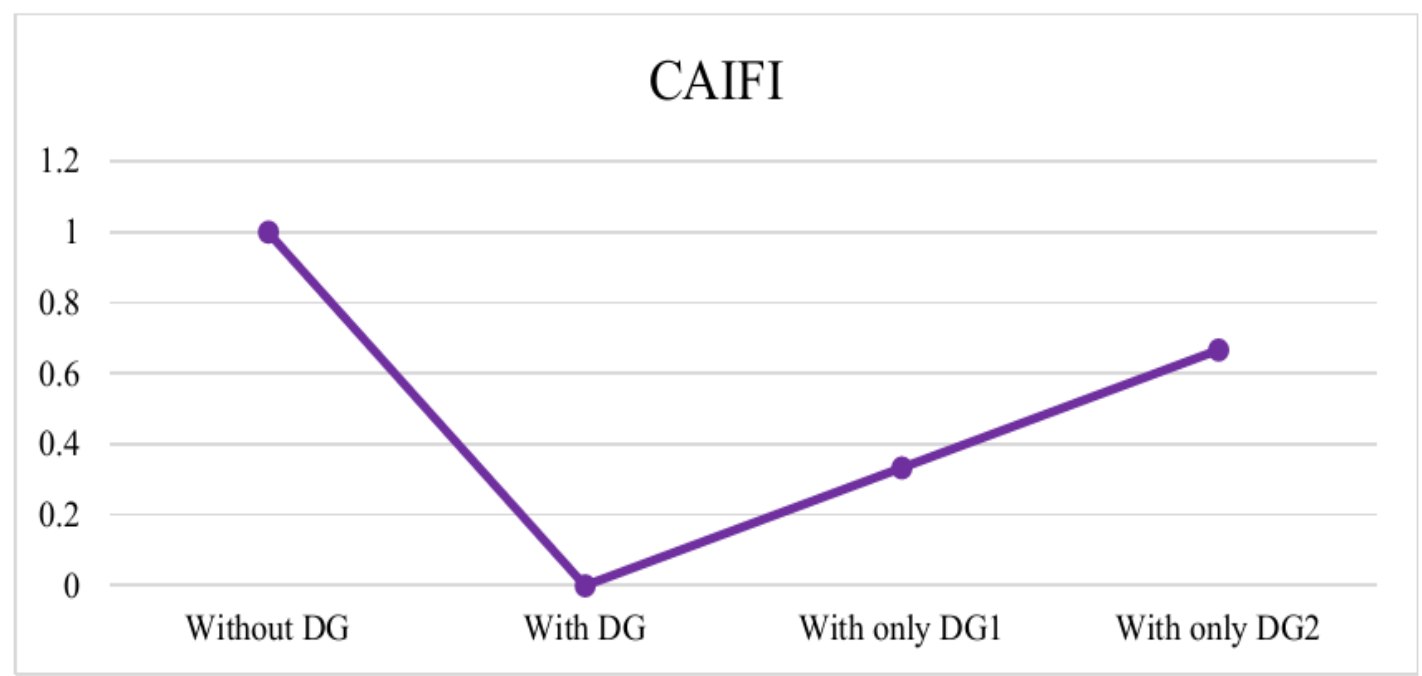

Figure 7. Results of CAIFI 


\section{Discussion}

Table 3 summarises the various system indices of the distributed generation system in the town of Kumba, Cameroon. It's clear that, with the distributed generation system added to the existing grid, population faces less energy outage. With DG, $100 \%$ of energy is supplied by the new grid as shown in figure 8 .

Table 3. System indexes with DG

\begin{tabular}{ccccc} 
System Index & Without DG & With DG & With only DG1 & With only DG2 \\
SAIFI & 121.67 & 0 & 0.59233 & 1.1847 \\
SAIDI & 851.69 & 0 & 0.21383 & 0.42767 \\
ASAI & 0.90278 & 1 & 0.99998 & 0.99995 \\
CAIFI & 1 & 0 & 0.33333 & 0.66667 \\
\hline
\end{tabular}

\section{ENERGY SUPPLY OF THE NEW GRID OF THE CITY OF KUMBA}

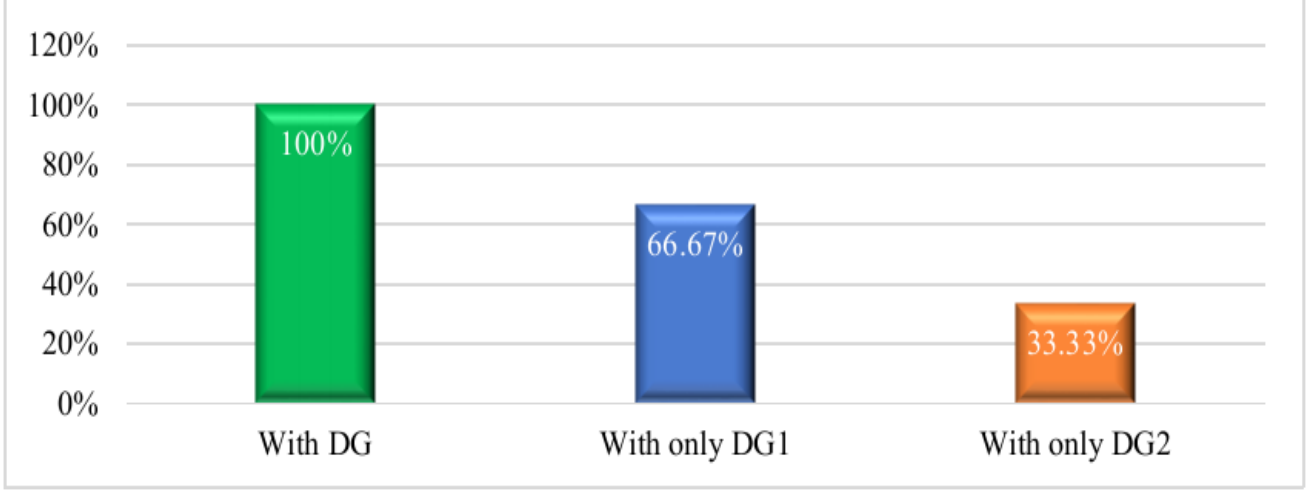

Figure 8. Energy supply of the new grid of the city of Kumba

\section{Conclusions}

The purpose of this research was to implement smart grid in the City of Kumba with the integration of distributed generation to optimize the current distribution grid. Upon researches and based on results obtained, it has been observed that applying ICT in the tradition grid will make it to be smart and therefore enhance power restoration time whenever a fault occurs. Solar farms were admitted to be DG sources due to their green nature to the environment and their availability to in the said city. DG in the new smart grid has dropped the number of interruptions of power observed by the system and consumers per year. The smartness of the grid and DG in it have corrupted the main feeder which was the backbone of the power supply in the city. Faults occurring within this line do no more cause blackout to the entire city. It can only cause one-third or two-third of customers not to have power if DG has a fault at the level of DG1 or DG2 respectively. This therefore proves that DG and smart grid in the grid have optimized electricity network of the city of Kumba by making it to be more reliable.

Author Contributions: All authors have read and approved the manuscript. Abraham Dandoussou made all the experimental work with the help of George Toh Lekunze. Pierre Kenfack helped Abraham Dandoussou with the basics of the experiment and how to use some key functions of MATALB®. George Toh Lekunze helps the team with proofreading of the paper to make it academically appropriate. All authors read and approved the final manuscript. 
Funding: This research receives no external funding

Data Availability Statement: The datasets analyzed during the current study are available from the corresponding author on reasonable request.

Acknowledgments: This research project went on smoothly thanks to the support of the Department of Electrical and Power Engineering, Higher Technical Teachers' Training College (HTTTC) Kumba, University of Buea, Cameroon.

Conflicts of Interest: "The authors declare no conflict of interest." "The funders had no role in the design of the study; in the collection, analyses, or interpretation of data; in the writing of the manuscript, or in the decision to publish the results".

\section{References}

[1] Green Energy and Technology, Smart Grids: Opportunities, Developments, and Trends, A. B. M. S. Ali, Ed., London: SpringerVerlag, 2013, p. 25.

[2] EG\&G Technical Services, Inc., Fuel Cell Handbook, Seventh Edition ed., Morgantown, West Virginia: U.S. Department of Energy, November 2004.

[3] Kenneth C. Budka, Jayant G. Deshpande and Marina Thottan, Communication Networks for Smart Grids: Making Smart Grid Real, London: Springer-Verlag, 2014, pp. 4-8, 111-126.

[4] T. A. Short, Electric Power Distribution Handbook, London: CRC Press, Taylor \& Francis Group, LLC, 2014, p. 800.

[5] H.O. Bansal and H.D. Mathur, "Distributed Generation Integration in Smart Grid Technologies," in Conference Paper, January 2012.

[6] Nur Asyik Hidayatullah, Blagojce Stojcevski, Akhtar Kalam, "Analysis of Distributed Generation Systems, Smart Grid Technologies and Future Motivators Influencing Change in the Electricity Sector," Smart Grid and Renewable Energy, 6 July 2011.

[7] Nur Asyik Hidayatullah, Zahir J. Paracha, Akhtar Kalam, "Impact of Distributed Generation on Smart Grid Transient Stability," Smart Grid and Renewable Energy, pp. 100-101, May 2011.

[8] A. Chowdhury. "Reliability Modeling of Distributed Generation". IEEE Transactions on Industry Applications, vol. 39, no. 5, pp. 1493-1498, 2003.

[9] Asatilla Abdukhakimov, Sanjay Bhardwaj, Gaspard Gashema, and Dong-Seong Kim, "Reliability Analysis in Smart Grid Networks Considering Distributed Energy Resources and Storage Devices," International Journal of Electrical and Electronic Engineering \& Telecommunications, vol. 8, no. 5, pp. 233-237, September 2019.

[10] Tawfiq M. Aljohani, Mohammed J. Beshir, "Distribution System Reliability Analysis for Smart Grid Applications," Smart Grid and Renewable Energy, vol. 8, pp. 240-251, 2017.

[11] Tawfiq M. Aljohani, Mohammed Beshir, "Matlab Code to Assess the Reliability of the Smart Power Distribution System Using Monte Carlo Simulation," Journal of Power and Energy Engineering, vol. 5, pp. 30-44, 2017.

[12] Basudev Da, Dr Bimal C Deka, "Impact of Distributed Generation on Reliability of Distribution System," IOSR Journal of Electrical and Electronics Engineering, vol. 8, no. 1, pp. 42-50, Nov-Dec 2013.

[13] S. Sivanagaraju, S. Satyanarayana, Electric Power Transmission and Distribution, India: Dorling Kindersley Pvt. Ltd, 2012.

[14] Kahrobaee, Salman, "Reliability Modeling and Evaluation of Distributed Energy Resources and Smart Power Distribution Systems," Theses, Dissertations, and Student Research from Electrical \& Computer Engineering, 2014.

[15] Suchismita Sujaya Duttagupta, "A Reliability Assessment Methodology for Distribution Systems with Distributed Generation," Thesis from Electrical Engineering, 2006. 